\title{
Growth Rate and Sensing Properties of Plasma Deposited Silicon Organic Thin Films from Hexamethyldisilazane Compound
}

\author{
S. Saloum* AND B. Alkhaled \\ Atomic Energy Commission of Syria (AECS), Physics Department, P.O. Box 6091, Damascus, Syria
}

(Received December 3, 2009; in final form January 29, 2010)

\begin{abstract}
Silicon organic thin films have been prepared by RF hollow cathode plasma chemical vapor deposition system, from hexamethyldisilazane (HMDSN) as the source compound, under different plasma conditions, namely feed gas and applied RF power. The feed gas has been changed from argon to nitrogen, and the power has been varied between $100 \mathrm{~W}$ and $300 \mathrm{~W}$ in $\mathrm{N}_{2}$ /HMDSN plasma. The plasma active species (electrons, ion flux rate, and UV radiation) contributing to the films growth mechanisms have been identified by electrical probes and optical emission spectroscopic analysis. The films have been investigated for their thickness and deposition rate, using quartz crystal microbalance, and sensing properties relating to humidity and gas $\left(\mathrm{NH}_{3}, \mathrm{CO}_{2}\right.$ and $\left.\mathrm{O}_{2}\right)$ sorptive investigations, using the piezoelectric effect of quartz crystals of the quartz crystal microbalance. The effect of the different plasma conditions on the plasma phase characteristics and deposited thin films properties, as well as the correlations between deposition rate and plasma characteristics and between sorptive properties, water contact angles and thin films surface morphology are reported.
\end{abstract}

PACS numbers: 52.70.Ds, 52.70.Kz, 81.15.Gh, 68.43.-h, 68.55.J-

\section{Introduction}

Silicon organic thin films deposited by plasma enhanced chemical vapor deposition (PECVD), from organosilicon sources, such as hexamethyldisiloxane (HMDSO) and hexamethyldisilazane (HMDSN), have attracted great interest for a variety of technological and industrial applications, like protective coatings, optical filters, chemical barrier coatings, scratch resistance coatings and humidity and chemical sensors $[1,2]$. The use of HMDSN precursor in PECVD process enables the fabrication of amorphous hydrogenated silicon carbonitride (a-Si-C-N-H) films [3, 4], these films have been demonstrated in different applications [5-10] such as surface protection, humidity sensors, hard anti-scratch coatings and diamond-like carbon coatings. It is of a great interest to investigate the sensing properties of these films, in particular that of humidity and ammonia gas, for the development of chemical sensors, because on the one hand, an accurate and reliable estimate of water vapor in different environments is an important pre-requisite for a variety of processes such as agriculture, weather control, drying technology, food processing, and textile technology, and on the other hand, ammonia gas is commonly used in many industries including industrial refrigeration

\footnotetext{
* corresponding author; e-mail: scientific@aec.org.sy
}

systems, since ammonia is a highly toxic and an explosively flammable gas, therefore proper safety monitoring procedures using gas sensors must be in place at all times to avoid serious accidental injury or death.

This paper is devoted to study the influence of changing plasma conditions (nature of feed gas and applied RF power) on the properties of thin films deposited from HMDSN precursor, such as deposition rate, sorptive properties of humidity and other gases, namely $\mathrm{NH}_{3}$, $\mathrm{CO}_{2}$ and $\mathrm{O}_{2}$. The plasma phase will be characterized using optical emission spectroscopy (OES) and electrical probes (single cylindrical Langmuir and planar probes) for understanding the deposition process.

\section{Experimental procedure}

The experimental setup of the plasma device, OES system, single Langmuir probe and the deposition system from liquid precursors such as HMDSN are described in detail in our previous works [11-14]. Briefly, the plasma source is a hollow cathode discharge (HCD) configuration, which consists of two coaxial tubes of $300 \mathrm{~mm}$ length. The inner tube is the hollow cathode and the outer-grounded tube forms the anode. Both cathode and anode are supplied with two rows of coaxial holes aligned to each other resulting in 30 plasma jets. The primary working gas (the feed gas) is fed into the cathode from both ends in order to maintain a constant gas 
pressure over the entire cathode length. RF power at $13.56 \mathrm{MHz}$ is applied to the cathode and intense primary plasma is generated, approaching plasma densities of $10^{11} \mathrm{~cm}^{-3}$ [12]. The coaxial holes in the cathode allow plasma jets to form and create the remote plasma. The overlap of plasma jets results in a very homogeneous plasma density distribution. The total pressure inside the plasma chamber has been controlled via an adaptive pressure controller valve supplied with a stepping motor. The HMDSN vapor is carried to the plasma chamber (stainless steel: $\left.50 \times 50 \times 50 \mathrm{~cm}^{3}\right)$ by helium $(35 \mathrm{sccm}$ flow rate), where the inlet line is positioned at a distance of $40 \mathrm{~mm}$ below the source.

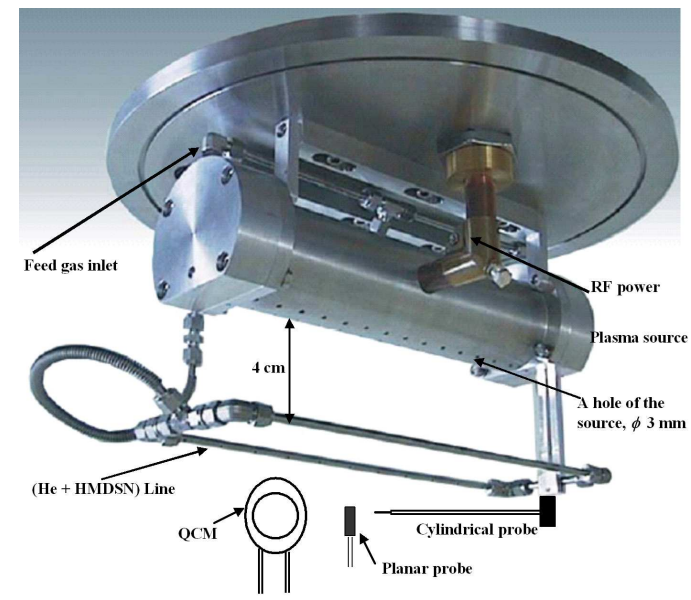

Fig. 1. A view of the plasma source inside the processing chamber with the operations positions.

The thicknesses and deposition rates of the deposited thin films have been monitored in situ using a quartz crystal microbalance located at a distance of $45 \mathrm{~mm}$ below the HCD source. Figure 1 shows a view of the HCD source and the positions of the electrical probes and the QCM head inside the process chamber. The humidity and gas $\left(\mathrm{NH}_{3}, \mathrm{CO}_{2}\right.$ and $\left.\mathrm{O}_{2}\right)$ sorptive properties have been studied using the QCM, where the same plasma vacuum chamber was used as a test chamber. The morphological properties have been investigated using a scanning electron microscope (SEM). Deposition has been carried out on four Au-coated quartz crystal resonators (about $6.0 \mathrm{MHz}$ frequency), under conditions of overall pressure of about $50 \mathrm{~Pa}$ and time of deposition of $20 \mathrm{~min}$, at constant flow rate of HMDSN $\left(Q_{\mathrm{HMDSN}}=12 \mathrm{sccm}\right.$ $(0.09 \mathrm{~g} / \mathrm{min}))$ and at four different plasma conditions as follows: $\mathrm{S} 1$ (feed gas: argon, $\mathrm{RF}$ power $=100 \mathrm{~W}$ ), S2 (feed gas: nitrogen, RF power $=100 \mathrm{~W}$ ), S3 (feed gas: nitrogen, $\mathrm{RF}$ power $=200 \mathrm{~W}$ ), $\mathrm{S} 4$ (feed gas: nitrogen, $\mathrm{RF}$ power $=300 \mathrm{~W}$ ). Commercial argon, nitrogen and helium gases with $99.999 \%$ purity and HMDSN (from Sigma-Aldrich) with $97 \%$ purity grade have been used. Basic plasma parameters (electron density, electron temperature, ion flux rate and UV radiation) have been derived using a cylindrical Langmuir probe, a planar probe, and the OES technique. In addition, the substrate temperature during the deposition process was monitored by a microprocessor-based thermocouple thermometer.

A quartz crystal microbalance can be used as a sensor due to the piezoelectric effect of the quartz material. Quartz crystal microbalances (QCMs) derive their sensor responses by changes in the oscillation frequency $(\Delta f)$ of a quartz crystal when exposed to a gas [15]. This change in frequency due to the addition of gas mass can be monitored and converted to a change in mass $(\Delta m)$ by the Sauerbrey relationship [16]:

$$
\Delta f=\left(f_{0}^{2} \Delta m\right) /(\rho N A),
$$

where $f_{0}$ is the resonant frequency of the quartz crystal (about $6.0 \mathrm{MHz}), \rho$ is the density of quartz $\left(2.65 \mathrm{~g} \mathrm{~cm}^{-3}\right)$, $N$ is the frequency constant of quartz $\left(1.67 \times 10^{5} \mathrm{~Hz} \mathrm{~cm}\right)$ and $A$ is the area of the thin film coated crystal. An important point to note is that the Sauerbrey equation is only applicable to uniform, rigid, thin-film deposits [17]. Thus, for soft and viscoelastic materials, the linear relationship between frequency and mass is not necessarily valid, because the materials do not fully couple to the crystal oscillations. Due to this, the QCM was for many years just regarded as a gas-phase mass detector, which is the case in the present work.

The ability of plasma polymer films, obtained from hexamethyldisilazane to absorb humidity (water vapor in air) and other gases such as $\mathrm{NH}_{3}, \mathrm{CO}_{2}$ and $\mathrm{O}_{2}$ in gas phase is studied by monitoring the changes in oscillating frequency of the quartz crystals coated with plasma thin films under the different plasma conditions mentioned above. Each of the studied gases $\mathrm{NH}_{3}, \mathrm{CO}_{2}$ and $\mathrm{O}_{2}$ was introduced to the evacuated test chamber at a constant pressure of 1 mbar, which corresponds to a gas volume ratio in air of about $900 \mathrm{ppm}_{\mathrm{v}}$. The humidity sorptive property has been studied in a different way. The humidity $(\mathrm{RH} \%)$ of atmospheric air inside the laboratory room is measured by a hygrometer to be $50 \%$ at room temperature $\left(25^{\circ} \mathrm{C}\right)$, which corresponds to 15 mbar water vapor partial pressure in atmospheric air (1000 mbar). To have 1 mbar of water vapor pressure in the test chamber, the humid air room was introduced to the vacuum test chamber at a pressure of about 65 mbar. The change of crystal frequency was recorded after 5 min of crystals exposure to each of the studied gases.

\section{Results and discussion}

\subsection{Plasma phase characterization}

The plasma phase consists of a wide spectrum of very reactive species (electrons, ions, free radicals and UV radiation). Therefore, during the plasma CVD process a competition between the film deposition process and the film etching process exists. The plasma diagnostic provides important information on the nature of the active species initiating the plasma CVD process. Therefore, the plasma phase, prior to the injection of HMDSN vapor precursor has been characterized. Because of the dominant role of electrons in the plasma phase reactions, 
it is important to measure both the electron density $\left(n_{\mathrm{e}}\right)$ and the electron temperature $\left(T_{\mathrm{e}}\right)$, where they were measured at the position of the QCM head using cylindrical single Langmuir probe as described in detail in a previous work [13]. The ion flux rate (ion bombardment of the surface) is also an important parameter in plasma processing, therefore it has been measured using a planar probe as described in [14]. The probe has a $7 \mathrm{~mm}$ diameter collector (area $A_{\mathrm{c}}$ ) and a $16 \mathrm{~mm}$ diameter guard ring. The technique of measurement is to apply a large negative bias to give a positive-ion saturation current $I_{\text {sat }}^{+}$. In our case we applied a bias of $(-100 \mathrm{~V})$ on both the collector and the guard ring. Thus, the positive ion flux rate $\Gamma_{\mathrm{s}}$ can be deduced from the relation

$$
I_{\text {sat }}^{+}=e A_{\mathrm{c}} \Gamma_{\mathrm{s}} \text {. }
$$

The UV and VUV photons play an important role in plasma CVD process [13]. Therefore the emitted light intensity integrated over the 200-400 nm UV range was measured using photon counting method, where the VUV (below $200 \mathrm{~nm}$ ) emission was not measured due to the limitation of our OES system in wavelength and in detector spectral response. Table I gives the variations of measured electron density, electron temperature, ion flux rate and UV radiation, as well as the substrate temperature under the different plasma conditions.

TABLE I

Variations of different plasma parameters as a function of plasma thin films deposition conditions $\mathrm{S} 1, \mathrm{~S} 2, \mathrm{~S} 3$, and $\mathrm{S} 4$.

\begin{tabular}{c|c|c|c|c|c}
\hline \hline $\begin{array}{c}\text { Plasma } \\
\text { conditions }\end{array}$ & $\begin{array}{c}n_{\mathrm{e}} \\
{\left[\mathrm{cm}^{-3}\right]}\end{array}$ & $\begin{array}{c}T_{\mathrm{e}} \\
{[\mathrm{eV}]}\end{array}$ & $\begin{array}{c}\mathrm{UV} \\
\text { radiation } \\
{[\text { arb.u. }]}\end{array}$ & $\begin{array}{c}\text { Ion flux rate } \\
{\left[\mathrm{cm}^{-2} \mathrm{~s}^{-1}\right]}\end{array}$ & $\begin{array}{c}\text { Substrate } \\
\text { temperature } \\
{\left[{ }^{\circ} \mathrm{C}\right]}\end{array}$ \\
\hline $\mathrm{S} 1$ & $3.0 \times 10^{9} \pm 10^{8}$ & $2.5 \pm 0.1$ & $1.0 \pm 0.05$ & $3.8 \times 10^{12} \pm 10^{10}$ & $30 \pm 1$ \\
$\mathrm{~S} 2$ & $2.1 \times 10^{9} \pm 10^{8}$ & $2.2 \pm 0.1$ & $1.3 \pm 0.05$ & $3.7 \times 10^{12} \pm 10^{10}$ & $45 \pm 1$ \\
$\mathrm{~S} 3$ & $2.7 \times 10^{9} \pm 10^{8}$ & $2.4 \pm 0.1$ & $1.5 \pm 0.05$ & $4.4 \times 10^{12} \pm 10^{10}$ & $55 \pm 1$ \\
$\mathrm{~S} 4$ & $3.3 \times 10^{9} \pm 10^{8}$ & $3.0 \pm 0.1$ & $1.6 \pm 0.05$ & $4.7 \times 10^{12} \pm 10^{10}$ & $70 \pm 1$
\end{tabular}

\subsection{Thin films properties}

\subsubsection{Deposition rate}

The film thickness and deposition rate for the prepared samples S1, S2, S3 and S4 were measured in situ using the QCM, and the results are depicted in Fig. 2. The scale of the thickness $(d)$ and deposition rate $\left(r_{\mathrm{d}}\right)$ can be drawn as follows: $\mathrm{S} 4<\mathrm{S} 2<\mathrm{S} 1<\mathrm{S} 3$. To explain this behavior of film thickness, we refer to the behavior of plasma characteristics presented in Table I. As reported in the literature [18-22], and without the presence of reactive molecular gas in the plasma (case S1), the electronic collisions with the precursor are mainly responsible of its fragmentation, whereas when nitrogen is present in the plasma phase, atomic nitrogen reacts with HMDSN in the gas phase, increasing its conversion and fragmentation, and it removes parts of the organic fraction of the film by means of gas-surface reactions [23]. The fact that the thickness of sample S1 is higher than sample S2 can be understood through the higher fragmentation of the precursor due to the higher electron density and the lower etching effect induced by UV photons. Nevertheless, as seen from Table I, the ions have approximately the same bombardment effect. In addition to this, the substrate temperature is an important factor which governs the growth rate, Blaszczyk-Lezak et al. [2] found that the increase of substrate temperature between $30^{\circ} \mathrm{C}$ and $200^{\circ} \mathrm{C}$ implies a decrease in growth rate of plasma de-

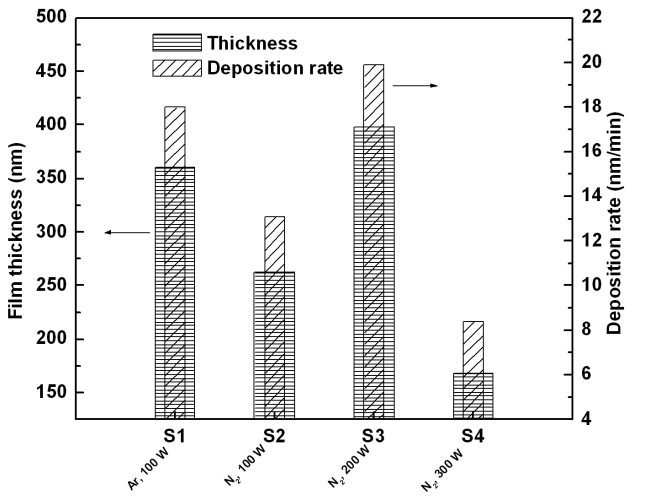

Fig. 2. Variation of deposited thin films thickness and deposition rate from HMDSN under the different plasma conditions.

posited thin films from tetramethyldisilazane precursor. In the present work the increase of substrate temperature between sample $\mathrm{S} 1$ and sample $\mathrm{S} 2$ is an additional factor, which explains the higher growth rate of sample $\mathrm{S} 1$ in comparison with sample S2. The comparison of films thicknesses for samples S2, S3 and S4 gives an idea about the effect of power on film growth kinetics. A non-linear growth of film thickness with RF plasma power is observed, and a maximum occurs at $200 \mathrm{~W} R \mathrm{RF}$ power 


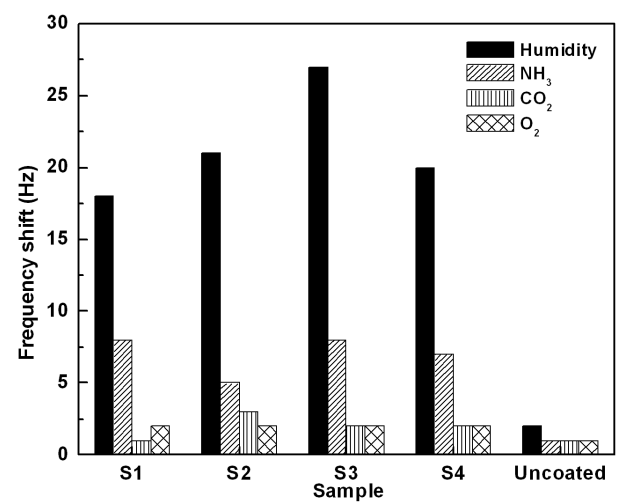

Fig. 3. Response of plasma thin films coated quartz crystals and uncoated one to humidity and $\mathrm{NH}_{3}, \mathrm{CO}_{2}$ and $\mathrm{O}_{2}$ gases. Filling pressure $=1$ mbar (concentration $\approx 900 \mathrm{ppm}_{\mathrm{v}}$ ), time exposure $=5 \mathrm{~min}$.

in this case. The appearance of this maximum and the lowest film thickness for sample $\mathrm{S} 4$ can be attributed to the increase of substrate temperature, UV radiation exposure, electron temperature and ion flux, as shown in Table I.

\subsubsection{Humidity and gas sorptive properties}

Figure 3 shows the QCM response to the different studied gases, in term of crystal frequency shift $(\Delta f)$, for coated crystals and uncoated one. It can be seen from the figure that the most significant response of the plasma thin films is attributed to the humidity sportive property. These films are able also to absorb ammonia with a sorption capability less than that of humidity, regarding the two other gases of carbon dioxide and oxygen. One can clearly observe the low response (about $2 \mathrm{~Hz}$ ) to these two gases compared to that of humidity (about $20 \mathrm{~Hz}$ ) and of ammonia (about $8 \mathrm{~Hz}$ ). In addition, the responses of plasma thin films coated crystals are comparable to that of uncoated one. The behavior of frequency shift due to ammonia sorption can be written as follows: $\Delta f(\mathrm{~S} 1)=$ $\Delta f(\mathrm{~S} 3)>\Delta f(\mathrm{~S} 4)>\Delta f(\mathrm{~S} 2)$, and the behavior of frequency shift due to humidity sorption can be written as follows: $\Delta f(\mathrm{~S} 3)>\Delta f(\mathrm{~S} 2)>\Delta f(\mathrm{~S} 4)>\Delta f(\mathrm{~S} 1)$. To explain these behaviors of films sorption properties, an attempt to correlate them with other films properties such as thickness, water contact angle and surface roughness, has been done. Water contact angle measurements of deposited thin films on quartz crystals were carried out with a contact angle system, to gain knowledge about the wettability properties of the plasma polymer thin films surface. The measured contact angles were found as follows: S1 $\left(90.3^{\circ}\right), \mathrm{S} 2\left(51.3^{\circ}\right), \mathrm{S} 3\left(24.6^{\circ}\right)$ and $\mathrm{S} 4\left(31.1^{\circ}\right)$.

In Fig. 4 there are shown the images of the water drop on the surface of films. The contact angles change from hydrophobic to hydrophilic values when feed gas is changed from argon to nitrogen, and with increasing applied RF power. Other authors achieved similar results, concerning similar conditions of sample (S1) for HMDSN plasma polymerized thin films. In Refs. [24, 25] they

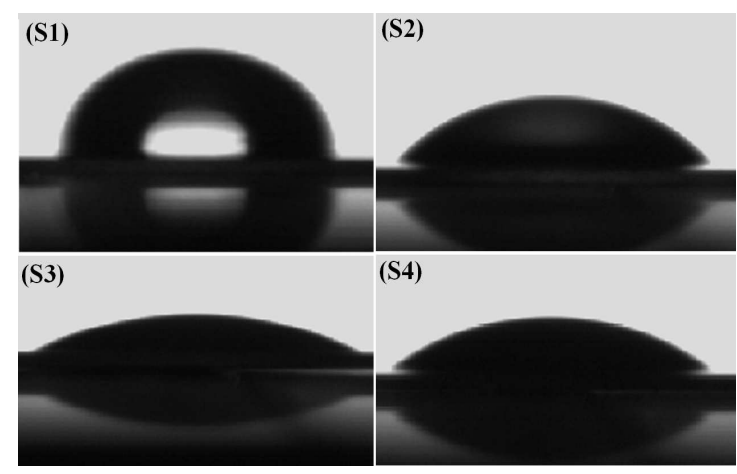

Fig. 4. The water contact angle on the surface of the samples S1, S2, S3, and S4.

found a contact angle of about $100^{\circ}$. Kraus et al. [5] measured water contact angles of HMDSN thin films in the range $\left[81^{\circ}-95^{\circ}\right]$. Da Silva et al. [6] found that HMDSN plasma polymerized films show a water contact angle of roughly $90^{\circ}$. The effect of surface structure and chemistry on hydrophobicity was further studied by Wenzel [26] and by Cassie and Baxter [27]. The Wenzel model introduced the effect of surface roughness in determining the hydrophobic nature of a surface, stating that the introduction of surface roughness causes the interfacial surface free energy to increase. The Cassie-Baxter model assumes the solid-liquid interface to have air pockets below the liquid droplet in surfaces having very high asperities, where the fraction of the solid surface in contact with liquid determines the degree of hydrophobicity. Both models predict an increase of water contact angle with increasing surface roughness.

Figure 5 shows the surface morphology of deposited thin films on quartz crystals observed by SEM. We can see that S1 sample has a rough surface, where big grains, whose mean size is about $290 \mathrm{~nm}$, are observed on surface, while the S2, S3 and S4 samples have a smoother surface with mean grains size of $166 \mathrm{~nm}, 162 \mathrm{~nm}$ and $174 \mathrm{~nm}$, respectively.

Table II illustrates the variations of ammonia and humidity sorption properties, water contact angle and surface properties (roughness root mean square (rms) and grain size) of the deposited films under the different plasma conditions. It can be noticed that the behavior of ammonia sorption property can be correlated somewhat to film thickness (Fig. 2), if sample (S1) is compared with samples (S2) and (S4) and sample (S3) is compared to sample (S2). Otherwise, the ammonia sorption property is hardly correlated to thin film surface properties. In the literature, it is found that Georgieva et al. [28] studied the ammonia sorptive properties of plasma polymer films, obtained from hexamethyldisiloxane (HMDSO), and found that the increase of the polymer thickness in the range of $0.09-0.24 \mu \mathrm{m}$ leads to an increase of the ammonia sorption capability of the samples. In regard of humidity sorption property, it can be observed from Table II that there is a good correlation between the contact angles val- 


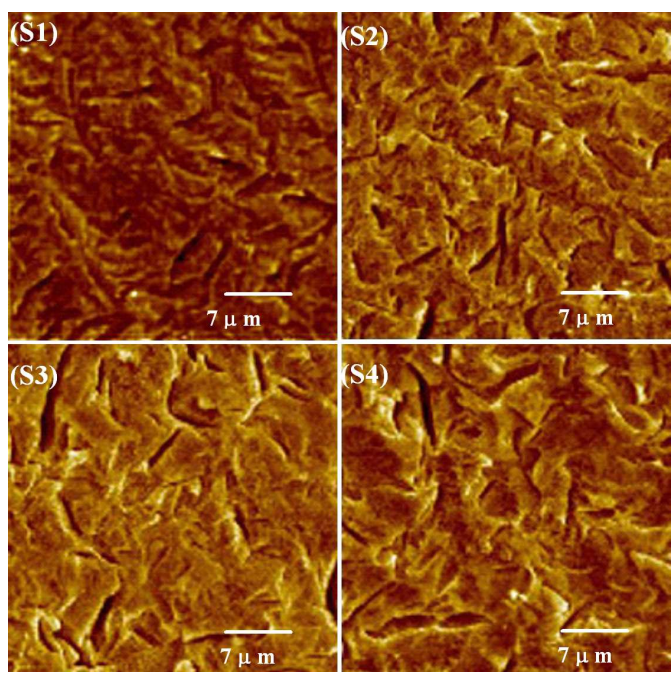

Fig. 5. SEM images of the samples S1, S2, S3 and S4. ues, the frequency shift and the surface roughness, while the correlation with film thickness is observed only for sample $\mathrm{S} 2$. The sample $\mathrm{S} 1$ is more hydrophobic than the sample $\mathrm{S} 2$, which is conjunction with the lower frequency shift due to humidity sorption and with the higher surface roughness. This result gives the effect of changing feed gas on thin films sorptive properties. The comparisons between samples S2, S3 and S4 reveal the effect of applied power. The observed minimum of surface roughness at $200 \mathrm{~W}$ applied power (S2) corresponds to the minimum of contact angle, the maximum of frequency shift and the maximum of film thickness for the same sample, which means that the more surface of the deposited thin film is rough the more it has a hydrophilic character and the less it absorbs water vapor.

TABLE II

Variations of ammonia and humidity sorption, water contact angle, surface roughness and mean grain size of the samples S1, S2, S3, and S4.

\begin{tabular}{c|c|c|c|c|c}
\hline \hline $\begin{array}{c}\text { Plasma } \\
\text { conditions }\end{array}$ & $\begin{array}{c}\text { Frequency } \\
\text { shift for } \\
\text { ammonia } \\
\text { sorption } \\
{[\mathrm{Hz}]}\end{array}$ & $\begin{array}{c}\text { Frequency } \\
\text { shift for } \\
\text { humidity } \\
\text { sorption } \\
{[\mathrm{Hz}]}\end{array}$ & $\begin{array}{c}\text { Water } \\
\text { contact angle } \\
{\left[{ }^{\circ}\right]}\end{array}$ & $\begin{array}{c}\text { Surface } \\
\text { roughness } \\
{[\mu \mathrm{m}]}\end{array}$ & $\begin{array}{c}\text { Mean } \\
\text { grain size } \\
{[\mathrm{nm}]}\end{array}$ \\
\hline S1 & $8 \pm 1$ & $18 \pm 1$ & $90.3 \pm 1.0$ & $2.31 \pm 0.02$ & $290 \pm 2$ \\
S2 & $5 \pm 1$ & $21 \pm 1$ & $51.3 \pm 1.0$ & $2.25 \pm 0.02$ & $166 \pm 2$ \\
S3 & $8 \pm 1$ & $27 \pm 1$ & $24.6 \pm 1.0$ & $1.75 \pm 0.02$ & $162 \pm 2$ \\
S4 & $7 \pm 1$ & $20 \pm 1$ & $31.1 \pm 1.0$ & $2.10 \pm 0.02$ & $174 \pm 2$
\end{tabular}

\section{Conclusions}

Plasma-polymerized thin films are obtained from HMDSN compound source in RF plasma system, under different plasma conditions of feed gas and applied RF power. The effect of changing plasma conditions on the plasma phase characteristics, and the obtained thin films growth rate and humidity/gas sorptive properties have been investigated. It has been found that changing the feed gas from a rare gas (argon) to a reactive molecular gas (nitrogen) implies a decrease in film deposition rate from $18 \mathrm{~nm} / \mathrm{min}$ to $13 \mathrm{~nm} / \mathrm{min}$ and a decrease of both the film surface roughness and the water contact angle (angle decreased from $90^{\circ}$ to $51.3^{\circ}$ ). Consequently, the humidity and gas sorptive properties have been modified. The obtained films with argon as a feed gas show higher ability to absorb ammonia and lower ability to absorb humidity than films obtained with nitrogen as a feed gas. In $\mathrm{N}_{2}$ /HMDSN plasma deposition environment, the applied power has been changed between $100 \mathrm{~W}$ and $300 \mathrm{~W}$, and the obtained films showed a maximum sorption response to humidity and ammonia at $200 \mathrm{~W}$ applied power, corresponding to a maximum of deposition rate, a minimum of surface roughness and a minimum of water contact angle $\left(24.6^{\circ}\right)$. This work shows that plasma-polymerized HMDSN thin films have promising characteristics for sensing humidity of ambient air, as well as sensing ammonia gas. In addition, it shows also that altering plasma conditions leads to the desired thin films properties.

\section{Acknowledgments}

The authors would like to thank Prof. I. Othman, Director General of AECS, for encouragement and permanent support. 


\section{References}

[1] A.M. Wrobel, M.R. Wertheimer, Plasma Deposition, Treatment, and Etching of Polymers, Academic, London 1990, p. 163.

[2] I. Blaszczyk-Lezak, A.M. Wrobel, T. Aoki, Y. Nakanishi, I. Kucinska, A. Tracz, Thin Solid Films 497, 24 (2006).

[3] A.M. Wrobel, I. Blaszczyk, A. Walkiewicz-Pietrzykowska, A. Tracz, J.E. Klemberg-Sapieha, T. Aoki, Y.J. Hatanaka, Mater. Chem. 13, 731 (2003).

[4] E. Vassallo, A. Cremona, F. Ghezzi, F. Dellera, L. Laguardia, G. Ambrosone, U. Coscia, Appl. Surf. Sci. 252, 7993 (2006).

[5] F. Kraus, S. Cruz, J. Muller, Sensors Actuators B 88, 300 (2003).

[6] M.L.P. Da Silva, I.H. Tan, A.P. Nascimento Filho, E. Galeazzo, D.P. Jesus, Sensors Actuators B 91, 362 (2003).

[7] H.D. Kuo, D.G. Yang, Thin Solid Films 374, 92 (2000).

[8] M.T. Kim, J. Lee, Thin Solid Films 303, 173 (1997).

[9] L.-Y. Chen, F.C.-N. Hong, Diamond Relat. Mater. 12, 968 (2003).

[10] D. Probst, H. Hoche, Y. Zhou, R. Hauser, T. Stelzner, H. Scheerer, E. Broszeit, C. Berger, R. Riedel, H. Stafast, E. Koke, Surf. Coat. Technol. 200, 355 (2005).

[11] S. Saloum, M. Naddaf, Vacuum 82, 55 (2007).

[12] S. Saloum, M. Naddaf, Vacuum 82, 66 (2007).
[13] S. Saloum, M. Akel, B. Alkhaled, J. Phys. D, Appl. Phys. 42, 085201 (2009).

[14] S. Saloum, M. Akel, B. Alkhaled, J. Phys. D, Appl. Phys. 42, 175206 (2009).

[15] A. Partridge, P. Harris, T. Hirotsu, S. Kurosawa, Plasma Polym. 5, 191 (2000).

[16] G. Saurbrey, Z. Phys. 155, 206 (1959).

[17] D.R. Denison, J. Vac. Sci. Technol. 10, 126 (1973).

[18] L. Zajickova, V. Bursikova, Z. Kucerova, D. Franta, P. Dvorak, R. Smid, V. Perina, A. Mackova, Plasma Sources Sci. Technol. 16, S123 (2007).

[19] D. Magni, Ch. Deschenaus, Ch. Hollenstein, A. Creatore, P. Fayet, J. Phys. D, Appl. Phys. 34, 87 (2001).

[20] D. Theirich, Ch. Soll, F. Leu, J. Engemann, Vacuum 71, 349 (2003).

[21] M. Goujon, T. Belmonte, G. Henrion, Surf. Coat. Technol. 188-189, 756 (2004).

[22] C.-H. Chen, M.-R. Yang, S.-K. Wu, Surf. Coat. Technol. 202, 2709 (2008)

[23] V. Kudrle, A. Talsky, J. Janca, Acta Phys. Slov. 55, 487 (2005).

[24] T. Hirotsu, J. Appl. Polym. Sci. 24, 1957 (1979).

[25] K.L. Mittal, N.K. Eib, A. Friedrichs, J. Appl. Polym. Sci. 25, 2435 (1980).

[26] R.N. Wenzel, Ind. Eng. Chem. 38, 988 (1936).

[27] A.B.D. Cassie, S. Baxter, Trans. Faraday Soc. 40, 546 (1944).

[28] V. Georgieva, E. Radeva, L. Spassov, Vacuum 58, 315 (2000) 